\title{
Poststernotomy mediastinitis: Early risk factors identified but hard to modify
}

\author{
Vincent Conti, MD
}

\author{
From the Division of Cardiothoracic Surgery, University of Texas Medical Branch, Galveston, Tex. \\ Disclosures: Author has nothing to disclose with regard to commercial support. \\ Received for publication Oct 4, 2017; accepted for publication Oct 9, 2017; available ahead of print Nov 4, 2017. \\ Address for reprints: Vincent Conti, MD, Division of Cardiothoracic Surgery, University of Texas Medical \\ Branch, 301 University Blvd, Galveston, TX 77555-0528 (E-mail: vconti@utmb.edu). \\ J Thorac Cardiovasc Surg 2018;155:1052 \\ $0022-5223 / \$ 36.00$ \\ Copyright $(c) 2017$ by The American Association for Thoracic Surgery \\ https://doi.org/10.1016/j.jtcvs.2017.10.008
}

The detailed analysis and prediction model for poststernotomy mediastinitis (PSM) presented by Nieto-Cabrera and colleagues $^{1}$ in this issue of the Journal adds useful insight into the variables worth assessing regarding the risks of PSM. They devised a risk score by looking at multiple preoperative and perioperative variables occurring within 24 hours of surgery, and then they applied it and validated it in a second cohort of patients. All data were drawn from their database, collected on 242 variables through a period of 6 years for nearly 4000 surgeries. The overall incidence of PSM was $2.36 \%$. They identified 4 preoperative risk factors with significant predictive value: age older than 70 years, chronic obstructive pulmonary disease, obesity (body mass index $>30 \mathrm{~kg} / \mathrm{m}^{2}$ ), and use of antiplatelet therapy. The perioperative variables were ischemic duration longer than 60 minutes, emergency reoperation, and prolonged intubation ( $>24$ hours). They then addressed in their discussion other risk factors identified in previous studies, and for the most part they presented reasonable conjectures as to why these did not show up in their list of significant risks. One important risk factor not well addressed was preoperative length of stay, ${ }^{2}$ which is a corrigible factor in many cases. They stated that many of their patients were transferred from other hospitals, and this variable was therefore not tracked in their database. They also did not see a significant increased risk in patients with diabetes, and they attributed this finding to good perioperative glycemic control. Their population of those undergoing coronary artery bypass grafting mostly had their procedures done off pump, and skeletonization of internal thoracic arteries, which other studies have found to be protective, ${ }^{3}$ was routinely used. It should be pointed out, however, that other studies have found a higher risk of PSM when bilateral internal thoracic artery grafting is used on patients with the combined risk factors of obesity and diabetes. ${ }^{4}$ This combination was not analyzed in the study of Nieto-Cabrera and colleagues.

One of the primary objectives of Nieto-Cabrera and colleagues ${ }^{1}$ was to identify risk factors that could be modified or corrected preoperatively or within 24 hours of surgery to

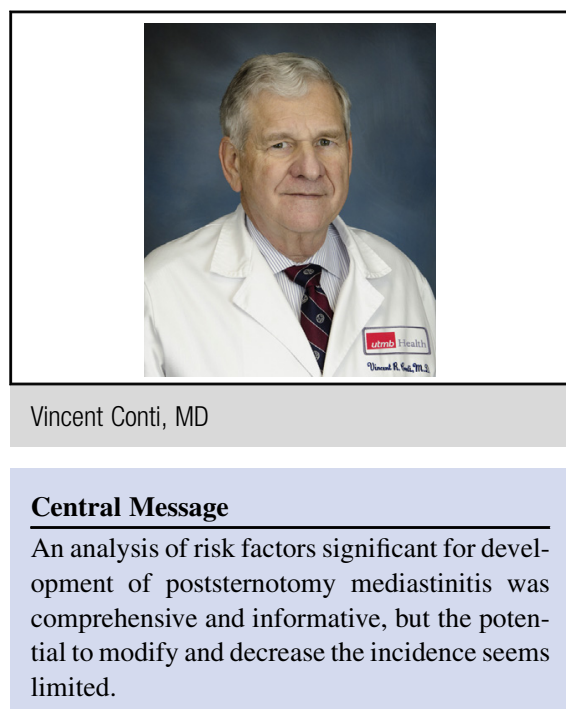

See Article page 1041.

decrease PSM. The only preoperative variable of this sort was the use of antiplatelet agents, which doubled the risk of PSM in their population. It is known that some surgeons will not stop clopidogrel 5 days before off-pump coronary artery bypass grafting, and the article of Nieto-Cabrera and colleagues ${ }^{1}$ suggests that this was their practice. An even higher risk factor for PSM was emergency reoperation within 24 hours, so one must ask whether the increased risk of bleeding was responsible for this antiplatelet effect, rather than the antiplatelet agents' effect on immune mechanisms. It is difficult to determine whether the remaining 2 risk factors, prolonged ischemic time and intubation time longer than 24 hours, are truly modifiable without compromising care in other ways. This study is a useful analysis, but it is difficult to see how it will help to decrease PSM.

\section{References}

1. Nieto-Cabrera M, Fernández-Pérez C, García-González I, Martin-Benítez JC Ferrero J, Bringas M, et al. Med-Score 24: A multivariable prediction model for poststernotomy mediastinitis 24 hours after admission to the intensive care unit. J Thorac Cardiovasc Surg. 2018;155:1041-51.e5.

2. Kelava M, Robich M, Houghtaling PL, Sabik JF III, Gordon S, Mihaljevic T, et al. Hospitalization before surgery increases risk for postoperative infections. J Thorac Cardiovasc Surg. 2014;148:1615-21.e3.

3. Kieser TM, Rose MS, Aluthman U, Montgomery M, Louie T, Belenkie I. Toward zero: deep sternal wound infection after 1001 consecutive coronary artery bypass procedures using arterial grafts: implications for diabetic patients. J Thorac Cardiovasc Surg. 2014;148:1887-95.

4. Deo SV, Shah IK, Dunlay SM, Erwin PJ, Locker C, Altarabsheh SE, et al. Bilateral internal thoracic artery harvest and deep sternal wound infection in diabetic patients. Ann Thorac Surg. 2013;95:862-9. 